\title{
On the Sources of the Inflationary Bias
}

\author{
by
}

Gustavo Piga, Columbia University

February 1998

Discussion Paper Series No. 9798-12

$$
\begin{aligned}
& \text { d. } 9792 \cdot 12 \\
& \text { pages } 22
\end{aligned}
$$


Comments are welcomed

This version: February 1998

\title{
On the Sources of the Inflationary-BiasA
}

\author{
By Gustavo Piga *
}

\begin{abstract}
Why do dynamic inconsistencies in monetary policy exist? In this paper we present a traditional model with output inefficiencies, but we allow for monetary policy to be influenced by the various constituencies in the economy, that pressure the Congress to in turn pressure the central bank to adopt a particular policy stance. We show that in this economy an inflationary-bias arises due to the lobbying pressures of outsiders. Furthermore, we show that if lobbying pressures are high enough, an inflationary-bias cannot be avoided for any finite level of central bank independence. We also show that introducing the realistic feature of lobbying pressures has an impact on the stabilization properties of monetary policy. When a supply shock occurs, the shock is totally absorbed by a forward-looking trade-union which has no costs of lobbying, independently of any finite degree of conservativeness and independence of the central banker, who has to accept an extreme increase in price instability. We show that monetary policy delegation is therefore sub-optimal in achieving price-stability compared to labor-market reforms meant to remove monopsonistic elements. However, the same structural policies will induce greater output instability by strengthening the power of conservative central bankers.
\end{abstract}

JEL: E52, E58, E31.
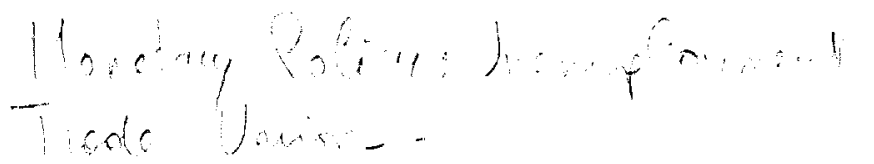

A I wish to thank John Higgins and Carl Walsh for helpful comments.

*Gustavo Piga, Columbia University, Department of Economics, New York (NY), 10027; tel.212/854-3669 fax 212/854-8059, EMAIL: gp19@columbia.edu 


\section{Introduction}

In a recent contribution, Jensen (1997) has provided a formal intuition for the argument raised by some authors (see Posen (1995)) that delegation of monetary policy into the hands of an independent central bank may not be a solution for eliminating the inflationary-bias in societies. In one sentence, this is because governments always have the option of renegotiating that delegation once expectations have been formed and can thereby reap the benefits of unexpected inflation. In equilibrium this is not a credible solution and an inflationary-bias is created even under a Walsh (1995)-contract type of arrangement.

Jensen (1997) achieves this result by positing an exogenous cost of renegotiating the reappointment of the central banker once expectations have been fixed. He concludes appropriately that his results have suggested that "recent emphasis on delegation has diverted attention away from the question of real importance: Why do dynamic inconsistencies exist?".

In this paper we try to provide an answer to this question. We present a traditional model with output inefficiencies subject to supply shocks where usually monetary policy produces an inflationary bias and has a role in stabilizing output. However, we allow for monetary policy to be influenced by the various constituencies in the economy, that pressure the Congress to in turn pressure the central bank to adopt a particular policy stance.

In our model insiders, after having chosen a desired real wage, set the nominal wage and observed the supply shock, lobby for a counter cyclical monetary policy to preserve their membership levels and avoid the consequences of hysteresis. Outsiders instead lobby the Congress for expansive unexpected monetary policies to enlarge the pool of employed workers.

We show that in this economy an inflationary-bias arises due to the lobbying pressures of outsiders. Furthermore, we show that if lobbying pressures are high enough, an inflationary-bias cannot be avoided fo any finite level of central bank independence. We thererefore conclude that one must shift Jensen's question on the causes of time-inconsistency to asking what causes these lobbying pressures to be particularly pronounced and in which situations they are more likely to

\footnotetext{
${ }^{1}$ Jensen (1997), p. 919.
} 
develop.

We also show that introducing the realistic feature of lobbying pressures has an impact on the stabilization properties of monetary policy. When a supply shock occurs, the shock is totally absorbed by a forward-looking trade-union which has no costs of lobbying, independently of any finite degree of conservativeness of the central banker, who has to accept an extreme increase in price instability. When lobbying costs are present, the supply shock is less than perfectly absorbed and the role of the central bank is re-established in diminishing price-instability for any given level of lobbying.

We show that monetary policy delegation is therefore sub-optimal in achieving price-stability compared to labor-market reforms meant to remove monopsonistic elements. However, the same structural policies will induce greater output instability by strengthening the power of conservative central bankers.

The next section describes the timing and preferences of the players involved. Section 3 solves the model and we draw some conclusions in section 4 .

\section{A political model of inflation}

\subsection{The timing of the game}

Where does the incentive for inflation surprises come from according to the traditional timeinconsistency set-up? Should we infer that central banks are inherently interested in unemploymentreducing or redistributive policies? Several authors have pointed out that this bias derives from political pressures on Central Banks from Congresss (Leijonhuvud and Heymann (1995), McCallum (1996a), and Patinkin (1993)). If this is the case a model of inflation that does not include these two actors explicitly is bound to provide a misrepresentation of the workings of the world. In this section we will provide a model which expands on Hetzel (1990) and Waller and Van Hoose (1992).

Our model has five players: Congress, the Central Bank, firms, Trade-Unions and Outsiders. The temporal setting of our game is the following:

1) before observing the supply shock, trade-unions choose a target real wage that minimizes the losses from employment variability around the current membership level and the political costs of 
lobbying to keep membership constant;

2) trade-unions fix inflation-expectation in their nominal contract not knowing the type of supply shock that will hit the economy, aiming at achieving the target real wage set in stage 1;

3) once the supply shock occurs and before monetary policy is implemented, trade-unions and outsiders engage in a costly lobbying effort which will affect the Congress stance on monetary policy. Outsiders only care about unexpected inflation so as to be employed.Trade-unions are assumed not be myopic. They therefore lobby for stabilizing output around their preferred level thereby trying to avoid that a supply shock generates hysteresis through the traditional channel of trade-union membership. ${ }^{2}$ The equilibrium level of lobbying is given by a Nash game between various lobbies;

4) the equilibrium intensity of lobbying determines the Congress preferences over monetary policy. The Congress - acting as a Stackelberg leader - then engages in a game with the Central Bank acting as a follower - that controls money supply. The game between the Central Bank and Congress takes place, given expectations formed in part 1) and 2) and the intensity of lobbying formed in part 3) and the supply shock.

5) After monetary policy is set firms choose the level of employment. ${ }^{3}$

The temporal setting of the game is similar to most models of monetary policy that allow a role for stabilization. We differ from the standard treatment only in that we micro-foundate the

\footnotetext{
${ }^{2}$ If membership changes in period $t$ because of a shock, then in period $(t+1)$ the number of members of the union will be different, leading to a different outcome than in period $t$, given that firms choose labor once the real wage is chosen by the monopoly union. In particular, negative shocks reduce permanently membership and raise the real wage of the remaining members, while positive shocks increase the number of employees, thereby diluting the bargaining power of unions.

${ }^{3} \mathrm{An}$ important issue that is usually left aside by the literature on monetary regimes is the one of why workers do not renegotiate nominal contracts after seeing the realization of the shock. While costs of renegotiating are usually an answer provided, in this model trade-unions suffer a cost from lobbying and we must therefore assume that those costs are lower than the ones of renegotiation. If the visibility of actions entails higher costs, then lobbying may indeed turn out to be less expensive than re-negotiating. In this regard, however, our paper is certainly not more enlightening than the literature. Jensen's paper (1997) suffers from the same problem when he assumes that nominal contracts are in place for longer periods than it takes for institutions to be changed.
} 
preferences of the Congress by introducing the possibility that the latter responds to political pressures of economic agents.

\subsection{The players of the game}

\section{2.a Firms}

Consider an economy with a production function :

$$
y_{i}=\alpha_{0} l_{i}+\epsilon
$$

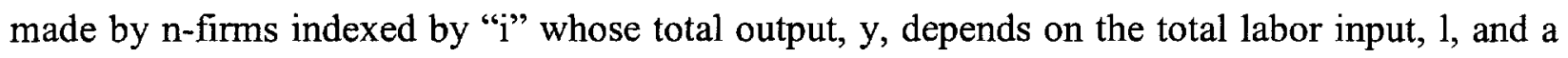
supply shock $\epsilon$. Each firm faces a monopoly trade union representing $\mathrm{N}$ workers, which fixes nominal wages based on optimal expected real wages and let firms make employment decisions based on profit maximization. Let all variables be expressed in logs and let $\mathrm{p}_{\mathrm{t}-1}^{\mathrm{s}}=0$, so that $\mathrm{p}_{\mathrm{t}}^{\mathrm{s}}$ can be interpreted as the inflation rate (the meaning of the superscript "s" will become clearer shortly). The labor market is therefore described by the following equations:

$$
\begin{gathered}
l^{d}{ }_{i}=-\alpha_{1}\left(w_{i}-p^{s}-\epsilon\right), \quad \alpha_{1}=\frac{1}{1-\alpha_{0}} \\
w-p^{e}=w^{*} \\
w_{i}=w^{*}+p^{e} \\
y_{i}^{\circ}=-\alpha_{0} \alpha_{1} w^{*}+\epsilon\left(1+\alpha_{0} \alpha_{1}\right)
\end{gathered}
$$

From now on set $\beta=\alpha_{0} \alpha_{1}$. The first equation represents labor demand for firm $i$, the second represents the trade union desired real wage, $w^{*}$, the third represents the contracted wage equation and the fourth the full-information level of output for firm i. When workers form their expectation $p^{e}$ they do not know the realization of supply stochastic shocks but only that they are white noise 
processes. The choice of the real wage is derived from the maximization of a representative forwardlooking trade-union facing each firm, that aims at preserving its membership equal to $\mathrm{N}$ while aware of the costs of such an objective (more on this later). Note that, given the supply shock $\epsilon$, membership $\mathrm{N}$ is preserved if and only if output in firm i equals $\alpha_{0} \mathrm{~N}+\epsilon^{4}$. Also, we will assume that the number of insiders in one period is determined by previous period employement.

Aggregate supply in this economy is given by:

$$
Y_{t}^{s}=n\left[-\beta w^{*}+\beta\left(p^{s}{ }_{t}-p_{t}^{e}\right)+(1+\beta) \epsilon_{t}\right]
$$

where $n\left(-\beta w^{*}+(1+\beta) \epsilon\right)$ is the full information output. Aggregate demand is given by:

$$
Y_{t}^{d}=m_{t}-p_{t}^{s}+v_{t}
$$

where $\mathrm{v}$ is a velocity shock which we will suppose for simplicity to be identical to zero.

It can be shown that the price level $p^{s}$ is equal to:

$$
p^{s}{ }_{t}=+n \beta w^{*}+m_{t}^{e}+\frac{1}{1+n \beta}\left(m_{t}-m_{t}^{e}-\epsilon_{t} n(1+\beta)\right)
$$

\section{2.b The Congress and the central bank}

Money supply, set by the Central Bank, determines the level of inflation $p^{s}$. Expectations $p_{t}^{e}$ are formed by trade-unions without knowledge of the realization of supply shocks. The money

\footnotetext{
${ }^{4}$ Choices of the nominal wage given expectations on a supply shock are studied by Gottfries and Horn (1986) and Blanchard-Summers (1986). Their trade-union had however different goals than ours in that it aimed at achieving the a higher real wage taking into account its (negative) effects on the probability of employment for the members of the union.
} 
supply is the result of a game played by the Central Bank and the Congress. While the Central Bank dislikes inflation, the Congress is pressed by different interest groups to use the money supply as a tool of economic policy. Both institutions suffer from a cost of disagreeing with one another.

We assume the following:

- The Congress minimizes the loss function $L^{c}$ by choosing the appropriate level of inflation to demand to the Central Bank, $p^{D}$ :

$$
\operatorname{Min}_{p} D \quad L^{c}=\left[k^{\cdot}\left(p_{t}^{e}-p_{t}^{D}\right)+\delta\left(p_{t}^{D}-p_{t}^{S}\right)^{2}\right]
$$

where $p^{D}$ is the inflation demanded by the Congress to the central bank, $p^{S}$ is the inflation supplied by the Central Bank, $p^{e}$ is the expectation of inflation included in the contracts and is therefore a given, $k$ is an index of the strength of the inflation constituency and $\delta$, which is strictly positive, is an index of Congress sensitivity to conflicts with the Central Bank. When $k$ is greater than zero the inflation constituency is stronger than the deflationary one. In this case the Congress will try to impose unanticipated inflation to the Central Bank. ${ }^{5}$

What determines the parameter " $\mathrm{k}$ " in equation (6) that stands for the taste for redistribution through inflation of the Congress? We will assume that it depends on pressures from lobbying groups, namely insiders (trade-unions) and outsiders, which the Congress internalizes so as to satisfy those interest groups:

$$
k=l^{t o t}=l^{T U}+l^{O U T}=\sum_{i=1}^{n} l_{i}^{T U}+l^{O U T}
$$

\footnotetext{
${ }^{5}$ Unexpected inflation or deflation is a powerful tool for governments to redistribute wealth across citizens or groups. Beetsma (1996) shows the effects in the Calvo (1988) set-up of such a redistributive tax in the presence of individuals with different nominal debt-holdings. That this constituency pressure on Congresss will end-up affecting the central Bank's behavior is noted by McCallum (1996b), p.10, when he argues that "... I would expect that the relative importance given to inflation and unemployment avoidance will be approximately the same by a Central Bank and the society of which it is a part."
} 
where $\mathrm{l}^{\mathrm{OUT}}$ is the total lobbying pressures by outsiders and $\mathrm{l}^{\mathrm{TU}}$ total lobbying pressures by the $\mathrm{n}$ tradeunions indexed by “ $i$ ".

- The Central Bank minimizes instead the following loss function by choosing the appropriate level of money supply:

$$
\operatorname{Min}_{m_{t}} L^{b}=\left[\gamma\left(p_{t}^{S}-p^{D}\right)^{2}+b\left(p_{t}^{S}\right)^{2}\right]
$$

subject to equation (5). $\gamma$ is a positive number representing the degree of "legal" dependence of the Central Bank on Congress ${ }^{6}$ where $\gamma=0$ represents complete independence and as $\gamma$ increases independence decreases, while $b$ is strictly positive and has the usual interpretation.

These objective functions present the realistic feature mentioned above that the Central Bank does not care about unexpected policies "per se", but because of the cost of disagreeing with Congress. The latter is subject to pressure from constituencies which we will show to be at the root of the inflationary process.

\section{2.c The lobbies}

The total level of lobbying pressures in this model is simplified to be the result of competing pressures from two classes of agents: from $\mathrm{n}$ trade unions, each of which produces a lobbying effort $1^{\mathrm{TU}}{ }_{i}$ for a total level of $\mathrm{I}^{\mathrm{TU}}$, and from outsiders, $1^{\mathrm{OUT}}$. The trade-unions, having already fixed their inflationary expectations and having observed the supply shock will lobby to preserve the level of membership within the union. This means that a positive supply shock will be countered with pressures on the Congress to be deflationary, so as not to enlarge the membership and have the trend

\footnotetext{
${ }^{6} \mathrm{As}$ it will become clearer later on, $\gamma$ is an indicator of formal or legal independence: effective independence will be given by $k \gamma$. The parameter $\gamma$ could in principle be affected by the dominant constituency in society, i.e. by $k$. For example, one might expect higher independence of the Central Bank where anti-inflationary constituencies are stronger. However, this effect is probably a long term one, since institutions change slowly over time. We concentrate on short-term issues and therefore $\gamma$ is a given.
} 
real wage decline. In the case of a negative supply shock the trade-unions will lobby for expansive monetary policies so as not to shrink membership in the next period. In one sentence, while tradeunions are selfish in that they do not care about outsiders, they are not myopic in that they understand the potential hysteresis embedded in defending a given real wage when supply shocks occur. ${ }^{7}$ Outsiders instead will lobby for an expansive unanticipated monetary policy so as to generate more employment. We will assume that outsiders can organize in one unique lobby.

Lobbying is costly. Trade union's i objective function can be formulated as follows:

$$
\min _{l_{i} T U} L^{T U_{i}}=\left[\left(\frac{\lambda}{2}\left(-\alpha_{0} N-\epsilon+y_{i}^{s}\right)^{2}+\frac{c \cdot n}{2}\left(l_{i}^{T U}\right)^{2}\right.\right.
$$

$c n^{l u}$ represent the marginal cost of lobbying, which we assume decreasese with the size of the tradeunion while $\lambda$ indicates the preference for output stabilization within the trade-union around the level of output that guarantees employment only to members of the union (if $\lambda$ is zero, this amounts to a myopic trade-union). When lobbying in the third stage of the game, trade-unions minimize (9) having observed the shock $\epsilon$. In the first stage of the game trade-unions will choose their real wage $\mathrm{w}^{*}$ and they will do so by minimizing the expected value of (9) without knowing the realization of the shock.

The objective function of the outsiders is the following:

$$
\operatorname{Min}_{l} \text { OUT } L^{\text {OUT }}=\left[\rho\left(p^{e}-p^{s}\right)+\frac{d(.)}{2}\left(l^{\text {OUT }}\right)^{2}\right]
$$

$d l^{O L}$ is the marginal cost of lobbying for outsiders and $\rho$ is the marginal gain from unexpected inflation. Note that the parameter $\mathrm{d}$ (.) could be a function of several variables: the size of the pool

\footnotetext{
${ }^{7}$ Blanchard-Fischer (chapter 9, p. 450) describe a similar forward-looking union once a supply shock has occurred, in the case in which unions do not discount future pay-offs. In their setting, however, unions choose the real wage directly. In our setting that would imply a renegotiation of the contract, which we have excluded (see footnote 3 ). However, we allow for lobbying activity on monetary policy which amounts to an indirect choice of the real wage and output combination.
} 
of involuntarily unemployed (as it increases the marginal costs of lobbying should decrease), the degree of discouragement from being an outsider (as it increases the marginal costs of lobbying should increase), etc.

\section{Solving the game}

We will look for a sub-game perfect equilibrium by solving the whole game backwards. We will therefore first examine the sub-game between Congress and Central Bank given the target real wage $\mathrm{w}^{*}$, inflationary expectations $p_{t}^{e}$ of wage-setters and the equilibrium level of lobbying by the latter and outsiders and the supply shock affecting the economy.

We assume that the Congress acts as a Stackelberg leader in setting $\mathrm{p}^{\mathrm{D}}$. We therefore first find the reaction function of the central bank with respect to the inflation demanded by Congresss, by minimizing ( 8 ) subject to (5), taking as given expected inflation embedded in contracts and the level of political pressures, $\mathrm{k}$. The central bank's reaction function is:

$$
m\left(p^{D}\right)=(1+\beta) n \in-(1+\beta n) n \beta w *+\frac{\gamma(1+\beta n) p^{D}}{(\gamma+b)}-\beta_{n m}{ }^{e}
$$

Where $\mathrm{m}^{\mathrm{e}}$ is the expectation of nominal money stock when contracts are signed and therefore without knowledge of the supply shock. Trade-unions, when setting contracts will expect money supply to be:

$$
m^{e}\left(p^{D}\right)=-n \beta w *+\frac{\gamma E\left(p^{D}\right)}{(\gamma+b)}
$$

where $E\left(p^{D}\right)$ is the expectation of the Congress's request of inflation before observing the supply shock. 
The Congress minimizes (6) subject to (5) and to central bank's reaction function (11). Doing so, we obtain the inflation demanded by the Congress:

$$
p^{D *}=\frac{k(\gamma+b)^{2}}{2 \delta b^{2}}
$$

Replacing (13) in (11) and using (12) and inserting in (5) we obtain the level of inflation conditional on the realization of the shock, the pressures " $k$ " of lobbying groups, expected inflation and the target real wage $\mathrm{w}^{*}$ :

$$
p^{S *}=\frac{k(\gamma+b) \gamma}{2 \delta b^{2}}
$$

It is worth noting what affects inflation in our system. The higher the net inflationary pressures arising from lobbies, the lower the legal independence of the central bank, the lower the anti-inflationary stance of the central bank the higher inflation. We now move to the previous stage of the game to determine lobbying pressures.

Trade-union " $i$ ", after seeing the realization of the supply shock, chooses the optimal level of lobbying $\mathrm{l}^{\mathrm{TU}}{ }_{\mathrm{i}}$ by minimizing (9) subject to supply in the industry (obtained with (3)) and to (14), while taking as given inflation expectations set in contracts, the real wage $\mathrm{w}^{*}$ and the level of lobbying by outsiders, $1^{\text {OUT }}$. Its reaction function is given by:

$$
l_{i}^{T U}=\frac{-2 \delta b^{2} \lambda \beta \gamma(\gamma+b)}{4 \delta^{2} b^{4} c n+\lambda \beta^{2} \gamma^{2}(\gamma+b)^{2}}\left[\frac{\beta \gamma(\gamma+b)}{2 \delta b^{2}}\left(l^{O U T}+\sum_{j \neq i} l_{j}^{T U}\right)-\beta p^{e}+\beta(\epsilon-w *)-\alpha_{0} N\right]
$$

We'll examine a symmetric equilibrium where $\mathrm{l}^{\mathrm{TU}}{ }_{\mathrm{i}}=\mathrm{l}^{*}$ for all $\mathrm{i}$ 's. Given the specification of the lobbying technology, it turns out that the aggregate level of lobbying by trade-unions, $1^{\mathrm{TU}}$ is constant and does not depend on the number of trade-unions: 


$$
l^{T U}=\frac{-2 \delta b^{2} \beta \gamma(\gamma+b) \lambda}{4 \delta^{2} b^{4} c+\lambda \beta^{2} \gamma^{2}(\gamma+b)^{2}}\left[\frac{\beta \gamma(\gamma+b)}{2 \delta b^{2}}\left(l{ }^{\text {OUT }}\right)-\beta p^{e}+\beta(\epsilon-w *)-\alpha_{0} N\right]
$$

Outsiders instead choose that level of lobbying that minimizes (10) subject to (14) and given inflationary expectations. It easy to show that:

$$
l^{\text {OUT }}=\frac{\rho \gamma(\gamma+b)}{2 \delta b^{2} d}
$$

Notice that, while the equilibrium lobbying level of trade-unions requires further passages to be determined, we can already comment on the equilibrium choice of outsiders, since their strategy is independent of the trade-union's ones. Indeed, from (17), since the level of $\mathrm{l}^{\text {OUT }}$ is always positive we see that outsiders will always ask for expansive monetary policies. The intensity of lobbying is greater the more the central bank is legally dependent and the lower the costs of lobbying.

Given (16), (17), (14) and (7) we can now turn our attention to the second stage of the game when trade-unions set nominal wages unaware of the realization of the supply shock. The expected inflation incorporated in nominal contracts is given by:

$$
p^{e}=\frac{\rho \gamma^{2}(\gamma+b)^{2}}{4 \delta^{2} b^{4} d}+\frac{\left(\alpha_{0} N+\beta w *\right)\left(\lambda \beta \gamma^{2}(\gamma+b)^{2}\right)}{4 \delta^{2} b^{4} c}
$$

Where $\mathrm{w}^{*}$ is the real wage chosen by trade-unions in the first stage of the game. Replacing (18) and (17) in (16) we find that the total lobbying level of trade-unions given a certain choice of the real wage is:

$$
l^{T U}=\frac{-2 \delta b^{2} \beta \gamma(\gamma+b) \lambda \epsilon}{4 \delta^{2} b^{4} c+\lambda \beta^{2} \gamma^{2}(\gamma+b)^{2}}+\frac{\left(\beta w *+\alpha_{0} N\right) 2 \delta b^{2} \lambda \gamma(\gamma+b)}{4 \delta^{2} b^{4} c}
$$


The level of inflation given the real wage chosen in the first stage of the game is therefore equal to:

$$
p^{s}=\frac{\rho \gamma^{2}(\gamma+b)^{2}}{4 \delta^{2} b^{4} d}+\frac{\left(\alpha_{0} N+\beta w *\right)\left(\lambda \beta \gamma^{2}(\gamma+b)^{2}\right)}{4 \delta^{2} b^{4} c}-\frac{\beta^{2} \gamma^{2}(\gamma+b)^{2} \lambda \epsilon}{4 \delta^{2} b^{4} c+\lambda \beta^{2} \gamma^{2}(\gamma+b)^{2}}
$$

In the first stage of the game trade-unions minimize the expected value of (9) not knowing the realization of the supply shock, by choosing an expected real wage $w^{*}$, subject to equations (19), (18) and (20). The real wage is chosen therefore so as to minimize expected costs of lobbying and expected deviations from the output level that guarantees employment to all $\mathrm{N}$ members of each trade-union. It is easy to show that the optimal solution to this problem yields:

$$
w^{*}=\frac{-\alpha_{0} N}{\beta}
$$

Equation (21) says that trade-unions choose a lower expected real wage the higher the membership that has to be attained. ${ }^{8}$ Inserting (21) in (18) and (19) yields additional insight on the choice of trade-unions:

$$
p^{e}=\frac{\rho \gamma^{2}(\gamma+b)^{2}}{4 \delta^{2} b^{4} d}
$$

\footnotetext{
${ }^{8}$ The costs of strategy (21) are not zero and increase with the variance of the supply shock. The more supply-shocks are volatile around their expected value the higher the variance output around its desired level given a certain lobbying effort and the higher the lobbying costs to achieve a given output level. Notice also that if the trade-union had no costs of lobbying the choice of the target real wage would be irrelevant and the loss function would equal zero.
} 


$$
l^{T U}=\frac{-2 \delta b^{2} \beta \gamma(\gamma+b) \lambda \epsilon}{4 \delta^{2} b^{4} c+\lambda \beta^{2} \gamma^{2}(\gamma+b)^{2}}
$$

(23)

Compare (18) and (19) with (22) and (23) respectively. From (23), we see that the choice of the real wage by trade-unions is meant to eliminate that component of the trade-unions expected costs that was known with certainty at the first stage and as such incorporated in the nominal wages and therefore irrelevant for output stabilization purposes, but still costly as for the lobbying component of the loss function.

Expression (22) is key for our purposes in that it shows that there is an inflationary-bias in this economy strictly related to the existence of the lobby of outsiders. The inflationary-bias is decreasing in the legal independence of the bank. However, we see that for any given level of legal independence there exists always values of $\rho$ high enough and of $d$ low enough for which legal independence is not sufficient to ensure effective independence, as defined in footnote 6 . If we imagine that $\rho$ increases with the strain of outsiders and that the costs of lobbying decrease the higher the pooling of unemployed, we see that recessions are a time in which the inflationary-bias can be potentially large. To echo Governor Burns, the Fed chairman during the oil crisis:

"Viewed in abstract, the Federal Reserve System had the power to abort inflation ... It did not do so because the Federal Reserve was itself caught up in the philosophical and political currents that were transforming American life and culture ... It is illusory to expect central banks to put an end to an inflation .... that is continually driven by political forces... (and that) will not be vanquished ... until new currents of thought create a political environment in which the difficult adjustments required to end inflation can be undertaken". 9

Equation (23) is important in several respects. First it shows us that the lobbying activity of trade-unions is unrelated to the inflationary-bias. The latter has already been incorporated in nominal wages by insiders, who are not concerned about it. However, non myopic-trade unions care about output stability to avoid the negative effects on membership that the phenomenon of hysteresis could

${ }^{9}$ From Timberlake (1993), pp. 345-346. 
bring about. When a negative supply shock occurs $1^{\mathrm{TU}}$ is positive, implying that trade-unions lobby for expansive monetary policies to avoid that membership will be permanently eroded in the next period. If positive shocks occur trade-unions will instead lobby for restrictive monetary policies to avoid the hiring of outsiders. Note that myopic trade-unions that do not care about output fluctuations $(\lambda=0)$ do not lobby, a costly activity, and expose themselves to hysteresis.

Replacing (17), (18) and (19) in (4) and (5) we are able to determine the value of inflation and output:

$$
\begin{gathered}
p^{s}=\frac{\rho \gamma^{2}(\gamma+b)^{2}}{4 \delta^{2} b^{4} d}-\frac{\beta^{2} \gamma^{2}(\gamma+b)^{2} \lambda \epsilon}{4 \delta^{2} b^{4} c+\lambda \beta^{2} \gamma^{2}(\gamma+b)^{2}} \\
Y^{s}=n\left[\alpha_{0} N+\epsilon-\beta\left[\frac{\epsilon 4 \delta^{2} b^{4} c}{4 \delta^{2} b^{4} c+\lambda \beta^{2} \gamma^{2}(\gamma+b)^{2}}\right]\right]
\end{gathered}
$$

The equation for output is particularly enlightening. The supply shock does not have its "classic" effects because of the political channel. Indeed, if trade-unions could lobby at no cost $(c=0)$, they would be capable of eliminating fully any variation in employment and ensure the appropriate level of output (the real wage would decline precisely as to re-establish the fullinformation natural rate). When trade-unions suffer a cost from lobbying, they weigh these costs against the distaste for output variability; in any case they do not succeed in stabilizing output completely except for in this extreme case. Notice that if trade-unions have no cost in lobbying, the inflation variability is highest.

When trade-unions are myopic, real wages are constant, output variability is maximized and price stability is ensured by the central bank.

\section{Conclusions}

Many authors have pointed out that central bankers are mainly concerned with price-stability and that pressures to deviate from that goal are brought by Congress subject to the pressures of 
constituencies interested in economic policy outcomes. To allow for such a feature in a simple timeinconsistency model allows us to derive the sources of the inflationary-bias: pressures from constituencies interested in unexpected inflation. While this result may not seem startling, it generates startling implications that are generally overlooked. First, monetary delegation to a central bank, even in the presence of costs of disagreement, will reduce the inflationary-bias only if the pressures from constituencies are relatively low. In our model lower lobbying costs or a higher desire for unemployment reducing policies will make any independent central bank more prone to produce an inflationary bias. This result is relatively robust, since it extends to a setting where the timeinconsistency arises in the government bonds market. ${ }^{10}$

The results seem to suggest - as a positive implication - that countries where the insiders are very powerful and create a mass of unemployed outsiders are more likely to generate inflationary biases than other countries. Note that if the current low inflation in many industrialized countries is the result of a reduced inflationary-bias, then it would have to be explained either by a decline in trade-union bargaining power that decreased the natural rate of unemployment or by some sort of reduced efficiency in the lobbying technology of outsiders (triggered maybe by an abandonment of the labor force). The model also suggests that while favoring a more organized outsiders may have beneficial effects at the bargaining table with employers, it may also have negative effects if outsiders will instead use their increased bargaining power in demanding expansive monetary policies. At the normative level these results justify better than previous analyses why monetary delegation is an imperfect tool for generating the desired inflation level, and point out that structural reforms of the labor market meant to decrease insider's power will have other benefits beside lowering the natural rate of unemployment.

One additional important result of our model is that the inflationary-bias is only part of the total bias occurring in this economy: another bias is due to the total level of lobbying activities exercised by outsiders, which achieves no better outcome than the one in the absence of lobbying

\footnotetext{
${ }^{10}$ See Pecchi-Piga (1997). However, they show that the inflationary-bias is not related to the extent of the nominality of contracts as usually suggested but to the strength of the tax-payers' lobby compared to the bondholders' lobby.
} 
and therefore amounts to a waste of resources. ${ }^{11}$

We also showed that stabilization policies meant to tackle shocks in the economy arise as endogenous responses to political pressures from constituencies. Stabilization of output around its (inefficiently low) level will be more effective the stronger the capacity of employed workers to have their desires represented through lobbying.

Enhancing atomistic labor markets and decreasing trade-unions capacity to organize themselves effectively may therefore generate a trade-off. While on the one hand it may eliminate the inflationary-bias by reducing outsiders' pressures, it may also increase output instability if the monetary policy is left in the hands of a central banker that is not pressed by Congress to achieve output stabilization because in turn lobbying costs are too high under atomistic markets. If the central bank turns out to care only about price-stability, then too much output instability will be generated if society cares also slightly about output instability. A conservative central banker will have its way only in a competitive world where in addition lobbying costs are prohibitively high.

The micro foundation of the time-inconsistency bias cannot end here. Two issues seems to be particularly worth exploring. What are the exogenous determinants of lobbying activities and how are these determinants likely to affect the biases in society? Can we provide a positive theory of why central bankers care about inflation more than society? Answering these two questions is likely to provide us with a greater understanding of the workings of fiat-money regimes.

\footnotetext{
${ }^{11}$ Brunner (1985), p.8, claims that this bias is inherent to every society: "the incentives to invest in the political process for purpose of acquiring wealth from others or for protective political action lowers the allocation of resources to socially productive activities."
} 


\section{$\underline{\text { References }}$}

Beetsma, Roel, M. W., "Servicing the Public Debt: The Role of Expectations: Comment", American Economic Review, June 1996, 675-679, vol. 86, n.3.

Blanchard, Olivier and Fischer, Stanley, Lectures on Macroeconomics, MIT Press, 1989.

Blanchard, Olivier and Summers, Lawrence, "Hysteresis and the European Unemployment Problem", NBER Macroeconomics Annual, 1986, 15-78.

Brunner, Karl, “The Poverty of Nations”, Business Economics, January 1985, 5-11.

Calvo, Guillermo A., "Servicing the Public Debt: the Role of Expectations", American Economic Review, September 1988, 78, n. 4, 647-661.

Gottfries, Nils and Horn, Henrik, "Wage Formation and the Persistence of Unemployment", The Economic Journal, December 1987, 877-884.

Hetzel, Robert, "The Political Economy of Monetary Policy" in The Political Economy of American Monetary Policy, ed. by Thomas Mayer, Cambridge University Press, 99-114, 1990.

Heymann, Daniel and Leijonhufvud, Axel, High Inflation, Clarendon Press, Oxford, 1995.

Jensen, Henrik, "Credibility of Optimal Monetary Delegation", American Economic Review, December 1997, vol. 87, n. 5.

McCallum, Bennett T. (1996a), "Inflation Targeting in Canada, New Zealand, Sweden, the United Kindom, and in General", NBER Working Paper Series, n. 5579, May 1996.

McCallum, Bennett T. (1996b), "Some Crucial Issues Concerning Central Bank Independence", NBER Working Paper Series, n. 5597, May 1996.

Patinkin, Don, "Israel's Stabilization Program of 1985, Or Some Simple Truths of Monetary Theory", Journal of Economic Perspectives, vol. 7, n. 2, Spring 1993, 103-128.

Pecchi, Lorenzo and Piga, Gustavo, "The Politics of Index-Linked Bonds", mimeo, 1997.

Posen, Adam S., "Declarations Are Not Enough: Financial Sector Sources of Central Bank Independence", NBER Macroeconomic Annual, 1995, 253-274.

Timberlake, R., Monetary Policy in the United States - An intellectual and institutional history, The University of Chicago Press, 1993. 
Waller, Christopher and Van Hoose, David, "Discretionary Monetary Policy and Socially Efficient Wage Indexation", Quarterly Journal of Economics, 1451-1460, November 1992.

Walsh, Carl E., "Optimal Contracts for Central Bankers", American Economic Review, March 1995 , $85,150-167$. 


\title{
1997-1998 Discussion Paper Series
}

\author{
Department of Economics \\ Columbia University \\ 1022 International Affairs Bldg. \\ 420 West 118th Street \\ New York, N.Y., 10027
}

The following papers are published in the 1997-98 Columbia University Discussion Paper series which runs from early November to October 31 of the following year (Academic Year).

The following is a website address where viewers may download some discussion papers. It is a project that is in progress, and therefore the site may not contain all recent working papers.

http://www.columbia.edu/dlc/wp/econ/index.html.

For Ordering Hardcopies:

Domestic orders for discussion papers are available for purchase at the cost of $\$ 8.00$

(U.S.) Per paper and $\$ 140.00$ (US) for the series.

Foreign orders cost $\$ 10.00$ (US) per paper and $\$ 185.00$ for the series.

To order discussion papers, please write to the Discussion Paper Coordinator at the above address along with a check for the appropriate amount, made payable to Department of Economics, Columbia University. Please be sure to include the series number of the requested paper when you place an order. 
1997-98 Discussion Papers

Economics Department, Columbia University

\begin{tabular}{|c|c|c|}
\hline $9798-01$ & Optimal Regulatory Transparency & Herk, L.F. \\
\hline $9798-02$ & Russia's Market Transition: Who Has Lost and How? & $\begin{array}{l}\text { Desai, } \mathrm{P} \text {. } \\
\text { Idson, } \mathrm{T} \text {. }\end{array}$ \\
\hline $9798-03$ & The Wage Arrears Crisis in Russia & $\begin{array}{l}\text { Desai, } \mathrm{P} . \\
\text { Idson, } \mathrm{T} \text {. }\end{array}$ \\
\hline $9798-04$ & Taxes Versus Legal Rules as Instruments for Equity & Sanchirico, C.W. \\
\hline $9798-05$ & Enforcement by Hearing: An Integrated Model of Evidence Production & Sanchirico, C.W. \\
\hline $9798-06$ & $\begin{array}{l}\text { Evidence Production, Adversarial Process and the Private Instigation of Suits } \\
12 / 95 \text { ) }\end{array}$ & Sanchirico, C.W. \\
\hline 9798-07 & Structural VAR, MARMA and Open Economy Models & $\begin{array}{l}\text { Dhrymes, P.J. } \\
\text { Thomakos, D. }\end{array}$ \\
\hline $9798-08$ & $\begin{array}{l}\text { Small Sample Properties of Certain Cointegration Test Statistics: A Monte Carlo Study (Revd. } \\
\text { from 7/96) }\end{array}$ & $\begin{array}{l}\text { Dhrymes, P.J. } \\
\text { Thomakos, D. }\end{array}$ \\
\hline $9798-09$ & How More Taxes Can Be Better Than Less: A Note On Aggregating Deadweight Losses & Lancaster, $\mathrm{K}$. \\
\hline $9798-10$ & $\begin{array}{l}\text { Environmental Self-Auditing: Setting the Proper Incentives for Discovering and Correcting } \\
\text { Environmental Harm }\end{array}$ & $\begin{array}{l}\text { Pfaff, A.S.P. } \\
\text { Sanchirico, C.W. }\end{array}$ \\
\hline $9798-11$ & Minimal Inclusive Sets in Special Classes of Games & Sanchirico, C.W. \\
\hline $9798-1 / 2 / 2$ & On the Sources of Inflationary Bias & Piga, G. \\
\hline
\end{tabular}

